\title{
Preschool Children's Problem-Solving Interactions At Computers and Jigsaw Puzzles*
}

\author{
Alexandra A. Muller \\ University of Minnesota \\ Marion Perlmutter \\ University of Michigan
}

\begin{abstract}
Preschool children's interactions while working on problem-solving tasks were investigated. In Study l, preschool children were observed working on learning games at a computer. Sharing, verbal and nonverbal instruction, and initiation of inferaction were recorded. Sixty-three percent of the children's time at the computer was spent with a peer, and they often spontaneously shared and instructed each other. Agerelated increases in time spent at the computer, as well as in self-initiation of interaction and sharing, were evident. No differences were found between boys' and girls' activities at the computer. In Study II, children were observed while working with jigsaw puzzles. In this context, children worked with peers just $7 \%$ of the time, and exhibited far fewer instances of cooperative interaction. The results of the research indicate that preschool children can engage in cooperative social interaction and instruction, and that under certain circumstances this activity may aid problem-solving. The research provides evidence that even children younger than school age can work effectively at computers. Moreover, the findings contradict common stereotypes about gender differences and social isolation from effects of computers.
\end{abstract}

The present research was primarily planned to document what happens when a computer is introduced into a preschool classroom. Thus far, there has been little research about computer use in classrooms, particularly in preschool classrooms. However, given the increasing prevalence of computers in our society, questions about how young children can or should be formally exposed to computers are important. Because it is likely that those who are exposed to computers early will be most comfortable and facile with them later, it is essential that the developmental

\footnotetext{
* This research was supported by grants from NIH (1ROS HDMHI1776 and 5R13 HD10650) and NIE (3-0032). Alexandra Muller was supported by the Center for Research in Human Learning while the observations were carried out. The authors would like to thank Edward DeAngelo and Sonja Hernandez for their contribution in data collection. They also are grateful for the enthusiasm and assistance of the former director of the University of Minnesota Child Care Center, Steven Sternberg, and the current director, teachers, students, and parents. Thanks to Bill Stixrud and Shirley Moore for providing PPVT scores.

Correspondence and requests for reprints should be sent to Marion Perlmutter, Institute of Gerontology, 300 N. Ingalls, University of Michigan, Ann Arbor, MI 48109-2007.
} 
level at which children can begin to profit from interaction with this technology not be underestimated. Moreover, since the introduction of computers at a young age is historically unprecedented, potential benefits and problems of this technology still need to be identified.

After informally observing a preschool classroom that had a computer, we decided to systematically examine the way preschool children interact with peers at the computer. During our preliminary observations, a high level of peer interaction at the computer seemed in contrast to the rather low level of peer interaction that was more typical in the preschool. This subjective impression seemed worthy of further pursuit.

Moreover, several theoretical perspectives highlight the probable importance of social interaction for cognitive development. For example, the Soviets (e.g., Vygotsky, 1978) have suggested that experience in joint problem-solving holds children's cognitive systems. Some American and European investigators have extended this view (Levin \& Kareev, 1980; Wertsch, McNamee, McLane," \& Burdwig, 1980), arguing that conflict of opinion among peers may induce disequilibrium and encourage cognitive development (Murray, 1972; Perret-Clermont, 1980).

Research in the area of peer tutoring suggests that elementary school children can effectively teach other children under specifically designed conditions (Allen, 1976; Cazden, Cox, Dickinson, Steinberg, \& Stone, 1979; Cicirelli, 1976; Johnson \& Johnson, 1975; Steward \& Steward, 1974). Some research also shows that school-age children can function in a collaborative, rather inain didactic partnership. In problem-solving tasks children have been found to offer opinions, hypotheses, and special expertise (Beaudichon, 1981; Cooper, 1980; Perret-Clermont, 1980). However, studies of peer interaction on complex laboratory classification tasks suggest that even school-age child teachers sometimes are unable to provide effective instruction (Ellis \& Rogoff, 1982; Steward \& Steward, 1974). They rely more on demonstration of tasks than adults, often do not allow adequate participation by a partner, and frequently require questioning by the learners to provide instructions (Ellis \& Rogoff, 1982; Cooper, Ayers-Lopez, \& Marquis, 1982; Steward \& Steward, 1974). It still is not known how regularly or effectively problem-solving interaction is possible for younger children.

In considering peer interaction as a possible forum for early acquisition of cognitive skills, young children's limited communication skills must be considered. Although some studies have shown that preschool children are capable of adapting their communication to the needs of listeners (e.g., de Villiers \& de Villiers, 1974; Maratsos, 1973; Menig-Peterson, 1975; Shatz \& Gelman, 1973), other studies have indicated the opposite (e.g., Fishbein \& Osborn, 1971; Flavell, Botkin, Fry, Wright, \& Jarvis, 1968; Glucksburg, Krauss, \& Weisberg, 1966; Krauss \& Glucksberg, 1969; for a review see Glucksburg, Krauss, \& Higgins, 1975). Such contradictory findings suggest that the information processing demands and ecological validity of the task probably play a role in children's ability to communicate 1eaningfully with others (Beaudichon, 1981; Flavell, 1977). It is essential, therefore, to determine whether young children are able to apply their communicative competencies in domains of specific interest. 
The present research involved an examination of preschool children's problem-solving interactions in two contexts, computers and jigsaw puzzles. The computer was chosen because it is a naturalistic problem-solving situation that is becoming ubiquitous in children's lives, raising concerns about its impact on interpersonal interaction. Puzzle-solving, a common childhood activity which is not thought to adversely impact social interaction, was chosen as a contrasting context. Both contexts allow, although do not require, joint problem-solving activity. The degree of isolated versus interactive activity was examined, as was the nature of children's interactions. In particular, observations were made about the amount of task participation partners allowed one another, the relative amounts of verbal and nonverbal instruction, and the degree to which the instructions were spontaneousiy offered versus requested.

\section{STUDY I}

The first study focused on preschool children's interactions in problem-solving with computers. Little research has yet investigated how computers are used in preschool classrooms. Moreover, research on children's computer use has rarely considered the social interaction it may promote. While it is popularly held that computers are socially isolating, some evidence suggests that computers stimulate interaction and collaboration. For example, Hawkins, Sheingold, Gearhart, and Berger (1982) observed more interaction when 8- to 11-year-olds worked on a computer than when they worked on noncomputer tasks. Levin and Kareev (1980) found the computer to be a naturalistic context which provided a rich environment for observing collaborative problem-solving interaction in 10-year-olds. Apparently, computers can provide opportunities for peer interaction, collaboration, and teaching.

\section{Method}

Subjects. The subjects in Study I were 27 children (13 males and 14 females) attending the University of Minnesota Child Care Center. Their mean age was 4 years, 4 months (range: 3 years, 8 months to 5 years, 7 months). The average Peabody Picture Vocabulary Test (PPVT) score of the 22 children for whom it was available was 116 (range: 92 to 160). This mean is approximately one standard deviation above the general population mean.

Background Measures. Children's preschool friendships were assessed by teacher ratings. Each of three teachers was independently shown an alphabetized list of the names of the children participating in the study. The teacher was asked to indicate the children that each of the subjects tended to play with most often. Children were designated as friends if two or more teachers reported them as consistent playmates. On the average, each child was rated as having 2 friends from the sample of 27 (range: $0-4$ ).

A questionnaire designed for the study asked parents to indicate whether their child had prior exposure to computers, and their children's curiosity concerning new objects, activities, adults, and children. Sixteen questionnaires were returned. 
Three mothers and three fathers used a computer at their job. Based on the questionnaire data and teacher reports, only two children had prior exposure to computers.

Apparatus and Stimulus Material. An Apple II computer with 48k memory, a single disk drive, and a standard keyboard was available in the children's classroom. The software used was a commercially produced diskette purchased from the Minnesota Educational Computing Consortium. There were three alphabet games, three number games, and three concentration-type memory matching games. In order to choose a program, the child had only to press a number corresponding to a picture which depicted the program they wanted. To respond to a program, a child needed only to press a single letter or number.

\section{Procedure}

Introduction to Computer. The children were introduced to the computer and programs by a teacher in groups of about 10 . In one half-hour introductory session they received verbal explanation as well as hands-on experience.

Use of Computer. The children's behavior with the computer was observed for 9 weeks. Each week observations were made during three $1 \frac{1 / 2}{2}$ hour free-play sessions. During these times, the children were allowed to work at the computer alone or with one other child. The children decided with whom they worked at the computer, as well as how long they remained at it. Since other activities were also available, this procedure usually allowed several groups the opportunity to use the computer during the 90 -min session.

Setting for Computer. The computer was placed in a central location against one wall of the child care center classroom and turned on with the program directory visible on the screen. This free access was designed to convey to the children that the computer was something to be readily approached and used.

The teachers, while supportive of the introduction of the computer, were not themselves very knowledgeable about computers or involved in the computer activity. They were asked to interact with the children at the computer in the same manner and to the same extent as they did when the children were engaged in other classroom activities. Teachers in this child care center usually let the children play independently, unless their help or company was actively sought or seemed to be needed. This same pattern was followed when children were at the computer.

Recording of Behavior at Computer. Observers coded each child's arrival and departure from the computer, the amount of time spent there, and social interaction. As may be seen in Table 1, three categories were used to describe the composition of social interaction (i.e., the presence of partners); these were none, teacher, and peer. Three categories were also used to describe the initiation of social interaction; these were self-requested, teacher-requested, and peer-requested. In addition, there were four categories to describe the form of interaction; these were sharing (turn- 
TABLE 1

Coding Categories

\begin{tabular}{ll}
\hline Category & \multicolumn{1}{c}{ Definition } \\
\hline $\begin{array}{l}\text { Composition of Interaction } \\
\text { None } \\
\text { Teacher }\end{array}$ & $\begin{array}{l}\text { No other present } \\
\text { Peer } \\
\text { Initiation of Interaction }\end{array}$ \\
$\begin{array}{l}\text { Self } \\
\text { Teacher }\end{array}$ & Neer present \\
Peer & Preceded breceded by request \\
Form of Interaction & Preceded by peer request \\
Sharing & Turn taking \\
Doing & Performing required action for another child \\
Showing & Demonstrating required action for another child \\
Explaining & Telling another child the required action \\
\hline
\end{tabular}

taking), doing (performing the action for another), showing (demonstrating the action), and explaining (describing the action). Finally, comments were recorded on any other noteworthy behavior, such as aggression. This coding scheme was derived from one reported by Bar-Tal, Raviv, and Goldberg (1982).

Interobserver reliability was calculated on approximately one-half of the observations. The observers were considered to have reached agreement when the initiation and form of an interaction were categorized identically by each observer. Agreement was calculated by dividing the number of agreements by the total number of behaviors recorded. The average interobserver agreement for all categories was $96 \%$, with a range of $88 \%$ to $99 \%$ for the various categories.

\section{Results and Discussion}

Overall, 203 episodes of child-computer activity were observed. All children interacted with the computer at least once. The range in number of interactions per child was 1 to 25 , and the mean was 8 . The average length of time of each episode was 18 mins. Social interaction that was observed during computer activity is summarized in Table 2.

For the most part, children seemed to prefer working at the computer with another individual, especially a peer. As shown in Figure 1,63\% of the time that children were at the computer they worked with a peer, $26 \%$ of the time they were with a teacher, and only $11 \%$ of the time they were alone. Approximately $18 \%$ of the peer contacts were between children rated as friends.

When children worked at the computer with a peer, they typically were actively interacting and cooperating. For example, as can be seen in Figure 2, 70\% of the peer interactions consisted of actively sharing use of the computer by taking turns. The remaining $30 \%$ of these interactions consisted of nonverbal and verbal assistance. 
TABLE 2

Summary of Social Interactions at Computer and Puzzles

\begin{tabular}{lcr}
\hline & Computer & Puzz/es \\
\hline Composition of Social Interaction & & \\
$\quad$ Alone & $11 \%$ & $55 \%$ \\
With Teacher & $26 \%$ & $38 \%$ \\
$\quad$ With Peer & $63 \%$ & $7 \%$ \\
Form of Social Interaction & & \\
Sharing & $70 \%$ & $0 \%$ \\
Doing & $10 \%$ & $8 \%$ \\
Showing & $9 \%$ & $28 \%$ \\
$\quad$ Explaining & $11 \%$ & $64 \%$ \\
Initiation of Social Interaction & & \\
Self & $78 \%$ & $50 \%$ \\
Teacher & $3 \%$ & $0 \%$ \\
Peer & $19 \%$ & $50 \%$ \\
\hline
\end{tabular}

Most of these helping interactions were initiated by the children themselves, rather than requested by teachers or peers. Specifically, as Figure 2 shows, $78 \%$ of the peer interactions were self-initiated, $19 \%$ were initiated by a peer, and only $3 \%$ were initiated as a result of a request by a teacher.

In order to determine whether there were age differences in the pattern of behavior, $t$-tests were performed to compare the data from the lower and upper half of the age range. The average age of the younger children was 3 years, 10 months ( $n$

\section{COMPUTER ACTIVITY Percentage of Time}

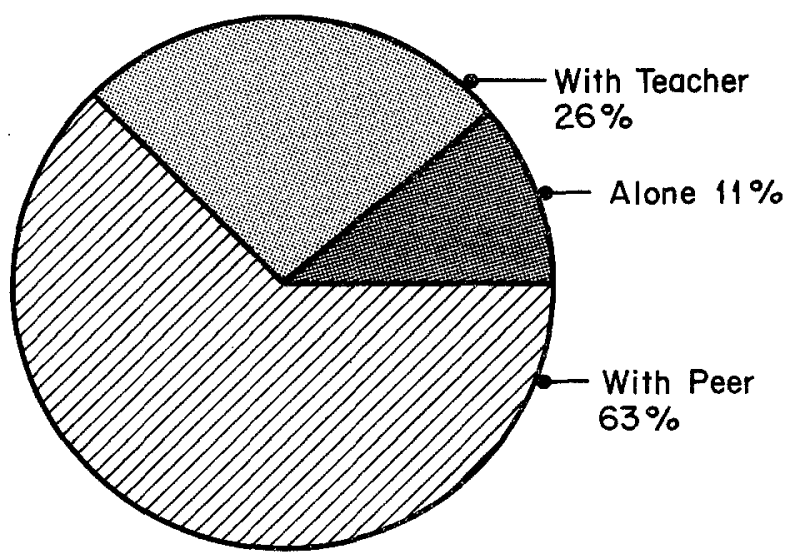

Figure 1. Distribution of composition of social activity at computer. 
COMPUTER ACTIVITY Initiation of Interactions

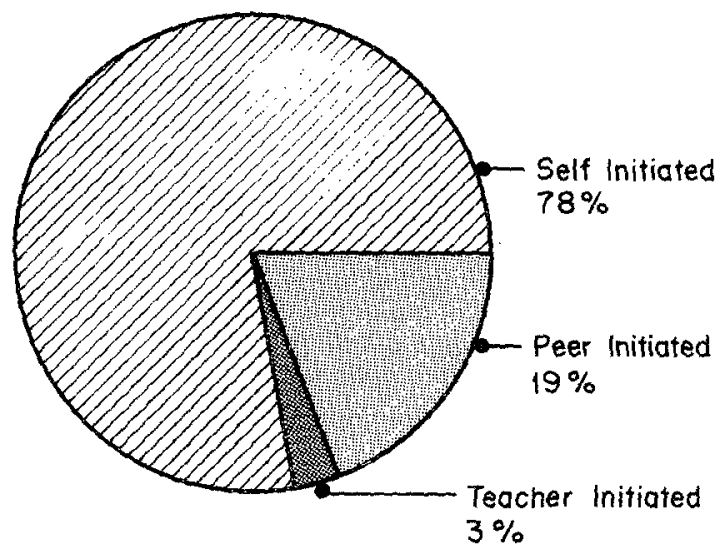

Figure 2. Distribution of form of sociol interaction at computer.

$=13$ ), and the average age of the older children was 5 years, 1 month $(n=14)$. For the sake of convenience, the groups will be referred to as 4- and 5-year-olds.

Age differences between 4- and 5-year-olds emerged in a number of areas. As Table 3 shows, 5 -year-olds spent more time at the computer overall than did 4-yearolds $(t=-2.00, p<.10)$. This difference can be accounted for by the increase in

\section{COMPUTER ACTIVITY Percentage of Interoctions}

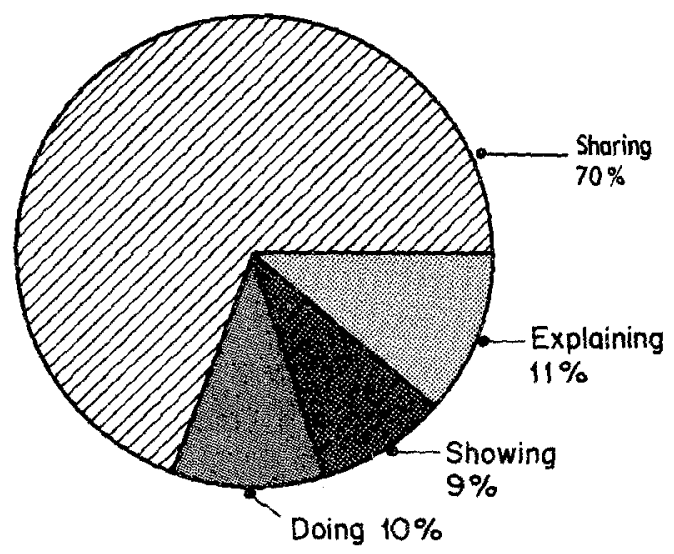

Figure 3. Distribution of initiation of social interaction at computer. 
TABLE 3

Mean Time in Minutes Spent Alone, With Teacher and With Peer at the Computer

\begin{tabular}{lccc}
\hline & 4-year-olds & 5-year-olds & $t$-value \\
\hline Total & 71.5 & 143.5 & $-2.00^{*}$ \\
Alone & 6.1 & 8.8 & $\mathrm{NS}$ \\
With Teacher & 18.2 & 19.5 & $\mathrm{NS}$ \\
With Peer & 47.3 & 115.3 & $-2.27^{*}$ \\
\hline${ }^{*} p<.10$ & & \\
$* p<.05$ & & &
\end{tabular}

time at the computer spent with peers $(t=-2.27, p<.05)$. The amount of time 4and 5-year-olds spent alone, or with teachers, did not differ between the two ages.

In addition, as may be seen in Table 4, 5-year-olds displayed significantly more turn-taking or sharing at the computer than did 4-year-olds $(t=-2.07, p$ $<.05$ ).

As may be seen in Table 5, 5-year-olds were also significantly more likely to be the initiators of sharing or instructing than were 4-year-olds $(t=-2.29, p$ $<.05$ ).

In order to determine whether there were gender differences in the pattern of behaviors, $t$-tests were performed to compare the data from boys and girls. No significant differences between girls and boys were found on any of the measures. Likewise, no differences emerged as a function of PPVT score or parent curiosity rating.

It appears that preschool children can work at a computer, and that in this context, they tend to work with another child more often than they work alone. Children not only seemed to prefer the presence of another child, but they were found to share use of the computer and were able to help each other in using it through demonstration and verbal explanations. Furthermore, most of this cooperative behavior was self-initiated. It is also noteworthy that there was a substantial

TABLE 4

Mean Frequency of Each Type of Peer Interaction at the Computer as a Function of Age

\begin{tabular}{lccc}
\hline & 4-year-olds & 5-year-olds & t-value \\
\hline Total & 30.0 & 50.4 & NS \\
Sharing & 12.1 & 29.6 & $-2.07^{*}$ \\
Doing & 2.9 & 8.6 & NS \\
Showing & 9.4 & 5.1 & NS \\
Explaining & 5.6 & 7.2 & NS \\
\hline${ }^{*} p<.05$ & & &
\end{tabular}


TABLE 5

Mean Frequency of Initiations at the Computer as a Function of Age

\begin{tabular}{lccc}
\hline & 4-year-olds & 5-year-olds & t-value \\
\hline Self-initiated & 11.8 & 36.6 & $-2.29^{*}$ \\
Teacher-initiated & 0.6 & 0.5 & NS \\
Peer-initiated & 4.7 & 4.9 & NS \\
\hline
\end{tabular}

${ }^{*} p<.05$

amount of cooperative interaction despite the fact that only about one-fifth of the peer interactions were between children rated as friends.

In summary, the presence of a computer seemed to provide a focus for problem-solving interaction among preschool children. The children were found to provide considerable help and instruction for each other with minimal intervention from a teacher. The fact that such helping was common supports the idea that computers can provide a context for social interaction which may contribute to the acquisition of problem-solving skills.

\section{STUDY II}

A second study was carried out to examine preschool children's problem-solving interactions in another context. While comparisons of involvement and social interaction at various classroom activities are limited by the inherent attractiveness and interest level of the activities, as well as the particular constraints and saliences of a given classroom, some benchmark for interpreting the data obtained in the study of computer activity was desired. Thus, children's interactions when working with jigsaw puzzles were examined. This activity was chosen because it shares some of the cognitive challenges of working at a computer and therefore was most relevant to questions concerning peer input to cognitive development. The study was designed to provide evidence concerning whether interaction around the computer was quantitatively or qualitatively different than interactions in the context of at least one other common intellectual task.

\section{Method}

Subjects. The subjects in Study II were a subset of the children who participated in Study I. They were children from the original groups who remained in the child care center for the summer. There was a total of 18 children $(8$ males and 10 females). Their mean age was 4 years, 4 months (range: 3 years, 5 months to 5 years, 1 month). Their mean score on the PPVT was 117 (range: 92 to 160).

Stimulus Material. The materials the children worked with were four attractive, new, wooden jigsaw puzzles. Each puzzle represented 1 of the 4 seasons: 
summer, fall, winter, spring. Each contained approximately 27 pieces, and had been advertised as appropriately challenging for 4- and 5-year-olds.

\section{Procedure}

Use of Puzzles. The children's behavior with the puzzles and each other was observed over 5 weeks, in each of three 1/2-hour free-play sessions per week. The children were allowed to work with the puzzles alone or in groups of two. They were also allowed to decide on their own how long they worked at the puzzies. Teachers let the children work independently, unless their help or company was actively sought or seemed to be needed. Thus, in a number of potentially important ways, the procedure matched the procedure used with the computer.

Setting for the Puzzles. The setting for the puzzles also was made as similar to the setting for the computer as possible. The four puzzles were available to the children, but only one was to be used at a time. A single intact puzzle was placed on a table, against a wall in a central location in the children's classroom. Upon completing one puzzle a child could choose another to replace it. This puzzle activity was freely available in the classroom during playtime, along with the other activities usually available. The computer was not present in the classroom during the time that observations of puzzles were carried out. Conversely, these puzzles had not been available during the computer observations.

Recording of Behavior at Puzzles. Observers coded each child's arrival and departure from the puzzle area, the amount of time spent with each puzzle, and social interaction. The coding scheme used in this study was the same as in Study I (see Table 1).

\section{Results and Discussion}

Overall, 49 episodes of child-puzzle activity were observed. All children interacted with the puzzles at least once. The range in number of episodes was 1 to 8 and the mean was 3 . The average length of time of each episode was 10 mins. The social interaction observed at puzzles is shown in Table 2.

The pattern of behavior with the puzzles was quite different than had been observed at the computer. First, as can be seen in Figure 4, the percentage of time children spent alone at the puzzles was considerable. While they had spent only $11 \%$ of their time alone at the computer, they were alone $55 \%$ of the time they were at puzzles. They worked with a peer only a very small percentage of the time they were at puzzles, $7 \%$ in contrast to $63 \%$ at the computer.

Of the small percentage of peer interactions at the puzzles, none were between children rated as friends. Furthermore, as Table 2 indicates, unlike at the computer, there was no turn-taking at the puzzles. Most of the children's interaction took the form of verbal explanations, which accounted for $64 \%$ of interactions. Finally, as is also indicated in Table 2 , interactions at the puzzles were rarely self-initiated by children. The interactions seemed more often to be in response to a direct question. 


\section{PUZZLE ACTIVITY Percentage of Time}

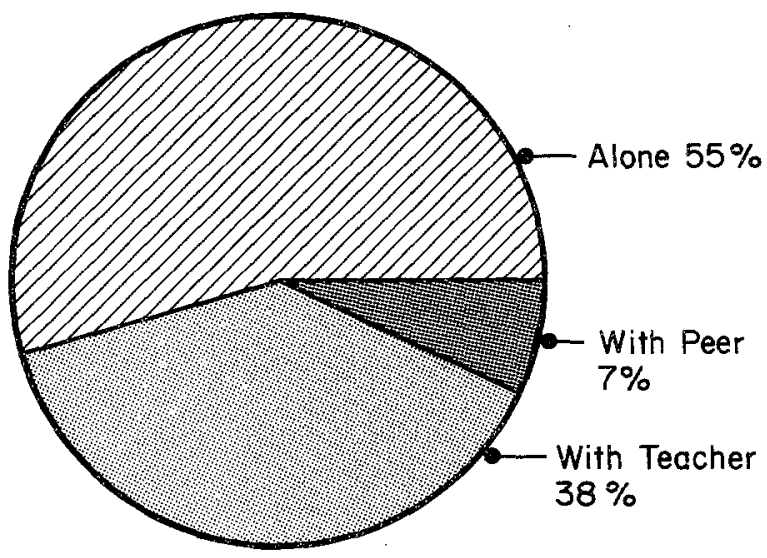

Figure 4. Distribution of composition of social activity at jigsow puzzles.

\section{GENERAL DISCUSSION}

Most past research concerning children's peer interactions and communicative skills has been performed under laboratory conditions with specially designed tasks. Such research involves work groups, time, and goals that are severely constrained by the experimenter. The present studies were carried out in a child care classroom in which primarily natural constraints were operative. Research in this setting should be especially useful in advancing understanding of young children's social and cognitive skills, as well as in determining the training or incentives that will be needed to introduce and promote computers and other activities in the classroom.

Across the two studies, there was a discrepancy in the amount of preschool peer interaction observed around problem-solving tasks. In Study I, there was considerable evidence of sharing or give and take at a computer, as well as some evidence of explaining and nonverbal assistance. In Study II, there was little evidence of social interaction during puzzle activity. These findings suggest that the cooperative behaviors observed in the computer setting may be, to some extent, a function of the computer, and may not necessarily be common or appropriate in all problem-solving situations that young children encounter.

A number of factors might account for greater interaction at computers than at puzzles. First, the novelty of the computer may have played a role in the greater interaction. Although all children had at least some prior exposure to the computer in their classroom, its novelty may have sparked a level of interest that will wane over time. Second, working at the computer was more open to view than working on puzzles. Since the computer screen was relatively large, upright, and easily seen from around the room, it may have drawn the children's attention. A third possible 
factor contributing to the high incidence of social interaction at the computer is that there was only one computer. Children may have been more constrained to work together than if several had been available. However, all of these possibilities seem less likely than might be expected, since the computer was not in use at all times when it was available. If the high level of interaction at the computer was attributable only to overdemand for it, no time of idle use would be expected. Finally, there is the interesting possibility that the nature of the computer task and its information processing demands may have stimulated social problem-solving, whereas the nature of puzzle-solving activity may have limited it. For example, responses to individual items in the computer tasks used in the present study were not dependent upon previous or subsequent responses, whereas the correct response in puzzlesolving depends upon the pieces already in place. Perhaps for young children the former activity allows easier entry into the problem-solving situation than the latter activity.

The research reported here suggests that computers can provide a focus for children to work together. The presence of a computer in the classroom does not necessarily spawn a classroom of computer hackers who ignore peers and teacher for the computer. Moreover, the findings indicate that even preschool age children can use a computer with a standard keyboard if the software provided is ageappropriate and the context is adequately structured. In addition, children did not require extensive structure or teacher input. Rather, they seemed to enjoy working at the computer with a peer. They appeared to seek each other's companionship, allowed partners significant participation through sharing, and provided verbal and nonverbal instruction for each other. These findings are in contrast to findings obtained in some earlier peer-tutoring studies (Cooper, Ayers-Lopez, \& Marquis, 1982; Ellis \& Rogoff, 1982; Steward \& Steward, 1974).

The research also uncovered several interesting developmental differences in problem-solving interaction at the computer. With age, children spent more time working with peers, engaged in more sharing, and were more likely to self-initiate help. The implications of these findings is that even preschool age children are able to interact effectively in a problem-solving situation. Furthermore, the computer context allows, and perhaps enhances, expression of such interactive skills, although even in this context age factors seem to contribute to increased sociability.

Although it has been suggested that boys are more likely to get involved with computers than are girls, this tendency was not apparent in the present preschool sample. Anecdotal reports from teachers and others (Benderson, 1983) suggest that by the elementary school years boys are making greater use of computers than girls. Although the finding of a lack of gender difference in preschool children's computer use should be replicated, it suggests that the early years may be an excellent time to introduce computers in order to promote equal comfort with this technology in girls and boys.

In summary, the results of the present research indicate that the common view of computer-human interaction as a solitary activity should be questioned. Computers actually may provide a rich opportunity for social problem-solving interaction 
and cognitive skill acquisition. The finding of early, and apparently productive, social interaction around a computer are encouraging, and might suggest that children should be given freedom to explore and teach each other about this new technology. While it will be important to have good, creative software available for children of all ages, as well as having supportive and stimulating teachers, considerable latitude might be called for when exposing children to this as yet not fully appreciated cognitive tool. The present cohort of very young children is unique, in that they are the first generation who can be exposed to computers at essentially the same time that they are exposed to other media and other cognitive tools. This early exposure is likely to produce mind and computer innovations that today's adults may be unable to develop on their own. The computer context today may offer a rare situation in which adults should truly learn from the young.

\section{REFERENCES}

Allen, V. L. (1976). Children as teachers: Theory and research on tutoring. New York: Academic. Bar-Tal, D., Raviv, A., \& Goldberg, M. (1982). Helping behavior among preschool children: An observational study. Child Development, 53, 396-402.

Beaudichon, J. (1981). Problem-solving, communication and complex information transmission in groups. In W. P. Dickinson (Ed.), Children's oral communication skills. New York: Academic.

Benderson, A. (1983). Computer-literacy, Focus, 11, 17-24.

Cazden, C. B., Cox, M., Dickinson, D., Steinberg, Z., \& Stone, C. (1979). "You all gonna hafta listen": Peer teaching in a primary classroom. In W. A. Collins (Ed.), Children's language and communication: The Minnesota Symposia on child psychology (Vol. 12). Hillsdale, NJ: Erlbaum.

Cicirelli, V. G. (1976). Siblings teach siblings. In V. L. Allen (Ed.), Children as teachers: Theory and research on tutoring. New York: Academic.

Cooper, C. R. (1980). Development of collaborative problem-solving among preschool children. Developmental Psychology, 16, 433-440.

Cooper, C., Ayres-Lopez, S., \& Marquis, A. (1982). Peer learning in the classroom: Tracing developmental patterns and consequences in children's spontaneous interactions. In L. C. Wilkinson (Ed.), Communication in the classroom. New York: Academic.

de Villiers, P. A., \& de Villiers, J. G. (1974). On this, that, and the other: Nonegocentrism in very young children. Journal of Experimental Child Psychology, 18, 438-447.

Ellis, S., \& Rogoff, B. (1982). The strategies and efficacy of child vs. aduit teachers. Child Development, 53, 730-735.

Fishbein, H. D., \& Osborne, M. (1971). The effects of feedback variations on referential communication of children. Merrill-Palmer Quarterly, 17, 243-250.

Flavell, I. H. (1977). Cognitive development. Englewood Cliffs, NJ: Prentice-Hall.

Flavell, J. H., Botkin, P. T., Fry, C. L., Wright, J. C., \& Jarvis, P. E. (1968). The Development of Role-Taking and Communication Skills in Children. New York: Wiley.

Glucksberg, S., Krauss, R. M. \& Higgins, E. T. (1975). The development of referential communication skills. In F. D. Horowitz (Ed.), Review of Child Development Research (Vol. 4). Chicago: University of Chicago Press.

Glucksberg, S., Krauss, R. M., \& Weisberg, R. (1966). Referential communication in nursery school children: Method and some preliminary findings. Journal of Experimental Child Psychology, 3 , $333-342$.

Hawkins, J., Sheingold, K., Gearhart, M., \& Berger, C. (1982). Microcomputers in schools: Impact on the social life of elementary classrooms. Journal of Applied Developmental Psychology, 3, 361373. 
Johnson, D. W., \& Johnson, R. T. (1975). Learning together and alone. Englewood Cliffs, NJ: Prentice-Hall.

Krauss, R. M., \& Glucksberg, S. (1969). The development of communication: Competence as a function of age. Child Development, 40, 255-256.

Levin, J., \& Kareev, Y. (1980). Problem-solving in everyday situations. The Quarterly Newsletter of the Laboratory of Comparative Human Cognition, 2, 47-51.

Maratsos, M. P. (1973). Nonegocentric communication abilities in preschool child̉ren. Child Development, 44, 697-700.

Menig-Peterson, C. L. (1975). The modification of communicative behavior in preschool-aged children as a function of the listener's perspective. Child Development, 46, 1015-1018.

Murray, F. B. (1972). Acquisition of conservation through social interaction. Developmental Psychology, 6, 1-6.

Perret-Clermont, A. N. (1980). Social interaction and cognitive development in children. New York: Academic.

Shatz, M., \& Gelman, R. (1973). The development of communication skills: Modifications in the speech of young children as a function of listener. Monographs of the Society for Research in Child Development, 38 (5, Serial No. 152).

Steward, M., \& Steward, D. (1974). Parents and siblings as teachers. In E. J. Mash, L. C. Handy, \& L. A. Hamerlynck (Eds.), Behavior modification approaches to parenting. New York: Brunner / Mazel.

Vygotsky, L. S. (1978). Mind in society. Cambridge, MA: Harvard University Press.

Wertsch, J. V., McNamee, G. D., McLane, J. B., \& Burdwig, N. A. (1980). The adult-child dyad as a problem-solving system. Child Development, 51, 1215-1221. 